\title{
DIAGNÓSTICO DA GESTÃO DOS RESÍDUOS SÓLIDOS NO MUNICÍPIO DE PALMELO (GO): UM OLHAR SOBRE AS POLÍTICAS PÚBLICAS
}

\author{
Rosilene Lopes da Cruz $^{(\mathrm{a})}$, Idelvone Mendes Ferreira ${ }^{(\mathrm{b})}$, Ralph Barbosa Rodrigues Alves ${ }^{(\mathrm{c})}$ \\ (a) Mestranda do Programa de Pós-Graduação em Geografia, Regional Catalão, Universidade Federal de Goiás. \\ Membro do NEPSA/RC-CNPq. rosirlenelopesdacruz@ gmail.com \\ (b) Professor do Programa de Pós-Graduação em Geografia, Regional Catalão, Universidade Federal de Goiás. \\ Coordenador do NEPSA/RC-CNPq. idelvoneufg@gmail.com \\ (c) Mestrando do Programa de Pós-Graduação em Geografia, Regional Catalão, Universidade Federal de Goiás. \\ Membro do NEPSA/RC-CNPq. ralphpmgo@ hotmail.com
}

\section{Eixo: Uso e ocupação das terras e legislação ambiental}

\begin{abstract}
Resumo/
Decorrente, sobretudo, da redistribuição das populações das zonas rurais para assentamentos urbanos, o processo de urbanização das sociedades humanas aconteceu de forma desigual em todo o mundo. Este fenômeno é característico dos países subdesenvolvidos ou em desenvolvimento, marcado pela elevada velocidade em que o êxodo rural acontece, bem como pela concentração da população nas cidades. Problemas relacionados à geração de resíduos, considerando-se o seu amplo significado, apresentam grandes riscos tanto ao ambiente quanto à saúde das populações que compõem a biota do planeta. Diante desta problemática, este artigo tem como objetivo discutir os problemas relacionados à produção de resíduos sólidos urbanos e seus riscos à saúde humana. Como metodologia, procederamse a observação do fenômeno, pesquisas bibliográfica e exploratória em campo, em coletânea de artigos, em imagens fotográficas, entre outros recursos metodológicos que sustentaram a análise e a reflexão sobre a produção de resíduos sólidos e suas consequências.
\end{abstract}

Palavras chave: Políticas públicas. Uso do solo. Consumismo. Resíduos sólidos. Impactos ambientais.

\section{Introdução}

O presente trabalho tem como objetivo refletir sobre o processo de urbanização e discutir os problemas relacionados à produção de resíduos sólidos urbanos no município de Palmelo (GO) e seus riscos à saúde humana. Desse modo, ao se analisar os problemas socioambientais que afetam a qualidade de vida da sociedade contemporânea, buscam-se possíveis soluções.

O processo de urbanização da sociedade humana contemporânea aconteceu de forma desigual em todo o mundo. Os países considerados "centrais" assistiram primeiramente aos seus processos de urbanização, apesar de outras civilizações antigas também apresentarem os seus espaços urbanos. Com o processo de colonização e o consequente subdesenvolvimento, a urbanização nos países periféricos consolidou-se apenas em meados do século XX, fruto da industrialização tardia nestes países. 
No Brasil, a migração de pessoas para outras regiões foi responsável pelo início da ocupação e, posteriormente, da urbanização da região Centro-Oeste, que se deu de forma lenta durante um longo período, dada a falta de infraestrutura das estradas e rodovias.

O processo de urbanização da cidade de Palmelo (GO) se configura pela prática do turismo religioso, no qual muitas pessoas, que visitam a cidade em busca de tratamento espiritual no Centro Espírita, encontram uma cidade calma e tranquila de se viver e acabam se mudando lá. Sua urbanização se dá também pela industrialização do município vizinho, Pires do Rio (GO), que vem oferecendo emprego a moradores das cidades vizinhas, decorrentes das atividades da Empresa vinculada ao Agronegócio, a Nutriza Agroindustrial de Alimentos S/A.

O fato é que os processos de urbanização estão ligados diretamente a uma industrialização e todos apresentam problemas tanto de caráter social quanto de caráter ambiental.

A partir do século XVIII, houve um grande aumento da população da região onde se localiza Palmelo (GO), trouxeram novos hábitos decorrentes da Revolução Industrial e movidos pelo consumismo, bem como diferentes preferências quanto ao tipo de mercadoria que seria consumida conforme a oferta de produtos no mercado. Isto gerou o aumento da geração de resíduos como nunca houvera antes, comprometendo cada vez mais a disponibilidade e a qualidade dos recursos naturais do planeta.

A exploração insustentável destes recursos é considerada hoje como um dos principais problemas que ameaçam o equilíbrio socioecológico mundial, pondo em risco o bem-estar da população e demais biota, colocando o homem diante de um paradigma ambiental. (OLIVA JUNIOR; FREIRE, 2013, p. 1).

O aumento dos problemas relacionados aos resíduos sólidos é ocasionado, geralmente, por processos de urbanização, porquanto o movimento de pessoas, conhecido como êxodo rural, causa o aumento da concentração populacional em áreas urbanas, contribuindo para o agravamento dos problemas advindos da produção de resíduos, em razão do aumento da produção e do consumo de bens e da falta de destinação adequada para desprezá-los. Em decorrência da industrialização resultante do estilo da produção e consumo em massa, atualmente, grande parte dessas mercadorias possui um caráter descartável, com pouquíssimo tempo de uso e duração, sendo rapidamente desprezada.

\section{Impactos socioambientias decorrentes da produção de resíduos}

Comumente, nos meios de comunicação, discute-se sobre a realidade ambiental do planeta. Este debate ganha ímpeto pela grande ocorrência de catástrofes que têm ocorrido nos últimos anos em várias regiões 
do globo, divulgadas por meio de relatórios técnico-científicos desenvolvidos por pesquisadores vinculados a diversas agências internacionais de pesquisas na área.

Surgem, então, questões consideradas relevantes no âmbito da reflexão deste tema. A primeira questão está assentada no entendimento de que os problemas ambientais, que assolam a sociedade contemporânea, são resultantes de um modelo de desenvolvimento econômico adotado pelas civilizações "modernas" e fundado no discurso do progresso. Dessa forma, só se consegue dar a esses problemas uma interpretação mais apurada se eles forem entendidos como sistêmicos que repousam sobre um modelo de economia e de vida posto em prática pelas sociedades modernas, especialmente, as do mundo ocidental. A segunda questão, que é ligada à primeira, está associada à ideia da complexidade da natureza. Assim, os problemas ambientais que têm ocorrido no planeta não devem ser analisados sem as ligações e nexos existentes entre a filosofia da própria natureza em conjunto com as práticas socioambientais humanas.

As transformações no mundo atual passam a ser mais intensas a partir do momento em que o ser humano deixou de ser nômade e começou a residir em locais fixos. Com o desenvolvimento de novas tecnologias, as mudanças passaram a ser mais rápidas e radicais. Após a primeira Revolução Industrial, em que as cidades se tornaram ambientes degradados, e, mais recentemente, com a crise no campo, o ser humano buscou melhores condições sociais nos centros urbanos, sendo estes, mais tarde, transformados em grandes aglomerados urbanos.

O ser humano construiu sua história, ao longo do tempo, por meio do constante processo de ocupação, apropriação e transformação do espaço natural. Durante este processo, acreditava-se que o crescimento econômico não tinha limites e que o desenvolvimento significava dominar a natureza e os seres humanos. Para Bernardes e Ferreira (2003, p. 17),

[...] as relações entre a sociedade e natureza desenvolvidas até o século XIX, vinculadas ao processo de produção capitalista, considerava o homem e a natureza como polos excludentes, tendo subjacente a concepção de uma natureza objeto, fonte ilimitada de recursos a disposição do homem. (BERNARDES; FERREIRA, 2003, p. 17).

A apropriação da natureza pelo indivíduo está sempre inserida numa determinada forma social. O período no qual se verifica com mais saliência a intervenção do homem no ambiente natural coincide com o avanço do capitalismo industrial, que provocou o avanço da exploração dos recursos naturais, em razão da considerável ampliação dos níveis de produção, sustentada pelo desenfreado aumento no consumo das diversas formas de matéria-prima extraídas da natureza.

Os problemas socioambientais começaram a ser sentidos com maior veemência no final do século XIX e início do século XXI, principalmente, pela exploração mais intensiva dos recursos naturais, juntamente com o crescimento demográfico que ocasiona o aumento na demanda pelos recursos básicos do planeta 
para a sobrevivência social humana. O grande dilema do mundo moderno é conciliar tal processo e a geração de um ambiente ecologicamente equilibrado.

É necessário mudar o pensamento e o modo de agir para se transformar a atual situação em relação ao ambiente, o que levará a uma mudança de paradigmas, passando de um modelo eminentemente econômico para um modelo ambientalmente viável, buscando um presente e um futuro mais promissores. Um dos objetivos desse novo paradigma é a sustentabilidade do planeta, cuja construção se dá a partir de novas relações entre o homem e o meio natural.

Nesse contexto, para Santos (2006, p. 156):

O meio natural correspondia a um tempo e espaço dados pelas relações entre a sociedade e natureza em que "[...] o homem escolhia da natureza aquelas suas partes ou aspectos considerados fundamentais ao exercício da vida [...]". Assim, o que era retirado da natureza, por meio de técnicas ainda que rudimentares, atendia ao princípio único da sobrevivência determinado pelas necessidades imediatas, pois o respeito ao potencial e aos limites da natureza eram praticados. (SANTOS, 2006, p. 157).

Contudo, outros estágios ou etapas da história do meio geográfico, segundo Santos, (2006), foram desenvolvidos depois daquele chamado de "meio natural". Impulsionados e mediados pela emergência de novas técnicas de relacionamento e exploração da natureza pela sociedade, o meio técnico e o meiotécnico-informacional surgem, respectivamente, como formas de organização socioespacial em que a dimensão artificial passou, paulatinamente, a se sobrepor à dimensão natural.

É tempo de alto desenvolvimento tecnológico/informacional, o qual, submisso às regras de um modelo econômico global, opera sob a égide da lógica do mercado. Este é o grande legado da modernidade, especialmente, das últimas décadas do século XX. A natureza, agora, responde aos projetos de uma sociedade que, diferentemente daquela existente no período do 'meio natural', tem se projetado no espaço sem considerar os seus limites e fragilidades.

A sociedade contemporânea está passando por uma série de problemas socioambientais. O grande desenvolvimento da técnica e da informação colocou desafios às sociedades atuais, nunca antes pensados na história da humanidade. Como disse Bauman (2007, p. 15), "a velocidade, e não duração, é o que importa." Isto nos conduz ao pensamento de que tudo é fugaz e efêmero, inclusive a vida, já que vivemos numa sociedade "líquido-moderna" caracterizada por "[...] uma vida precária, vivida em condições de incerteza constante." (BAUMAN, 2007, p. 8). Um dos maiores desafios da sociedade contemporânea é o de se desfazer do próprio lixo por ela produzido, uma vez que trata-se de uma coletividade que se identifica pelo poder de consumo e, consequentemente, gera resíduos. 
Para refletir sobre os resíduos sólidos urbanos é necessário levar em conta os aspectos espaciais, ambientais, de saúde, sociais, culturais e institucionais. A questão central que se coloca é a seguinte: o que se fazer com os resíduos?

Em seus estudos, Jacobi (2012, p. 31) diz que:

Um dos desafios é a necessidade de definirmos as melhores alternativas a serem adotadas [...]. [...]pois todos nós estamos envolvidos, principalmente nas ideias de se produzir menos, de reutilização e reciclagem. (JACOBI, 2012, p. 31).

A partir deste conceito, o ideal seria diminuir o consumo, reutilizar e reciclar. Nesse contexto, Souza (2016, não paginado) explica que "impacto ambiental é a alteração no meio ambiente por determinada ação ou atividade". Hodiernamente, a Terra enfrenta fortes sinais de transição. O homem está revendo seus conceitos sobre a natureza. Esta conscientização gera novos paradigmas, o que determina novos comportamentos e exige novas providências na gestão de recursos do meio ambiente.

A legislação correlata em vigência não evidencia se o causador da degradação é o ser humano em si ou até mesmo um fenômeno natural, seja ele resultante de atividade antrópica ou não. O que fica explícito é que o impacto socioambiental se caracteriza como dano negativo ao meio ambiente e à sociedade, colocando em risco o equilíbrio e o bem-estar da população.

Diante disso, Jacobi (2012, p. 31) destaca que, entre alguns aspectos do cenário brasileiro, aproximadamente $80 \%$ da população vive em áreas urbanas ao mesmo tempo em que a geração de resíduos sólidos per capita está aumentando cada vez mais, bem como a sua complexidade e periculosidade.

A geração média de resíduos sólidos no Brasil tem se situado quase no patamar dos países desenvolvidos. Estima-se que são geradas entre 140.000 toneladas/dia e 173.500 toneladas/dia de resíduos urbanos. Cada um de nós produz, por dia, aproximadamente 1kg de resíduos (GOLDEMBERG, 2012, p. 14).

Vale destacar que o início deste problema se deu há dois séculos, quando Malthus $(1959$, p. 8) "observou na Inglaterra, naquela época, que a população crescia de acordo com uma progressão geométrica, ao passo que a atividade agrícola crescia numa progressão aritmética", ou seja, linearmente. Este autor temia que a explosão populacional acabasse provocando fome no mundo. Contudo, com o grande aumento populacional em todas as partes do globo, outros problemas, além da fome, vieram à tona. Um deles é o do excesso de consumo de recursos naturais e, por conseguinte, a geração de resíduos.

$\mathrm{Na}$ atual fase da globalização e com avanço do capitalismo, impulsionado pelos meios de comunicação que incentivam o consumo sem limites, "[...] estamos condenados a conviver com uma quantidade de coisas e objetos produzidos e descartados cada vez maior.” (GOLDEMBERG, 2012, p. 14). 


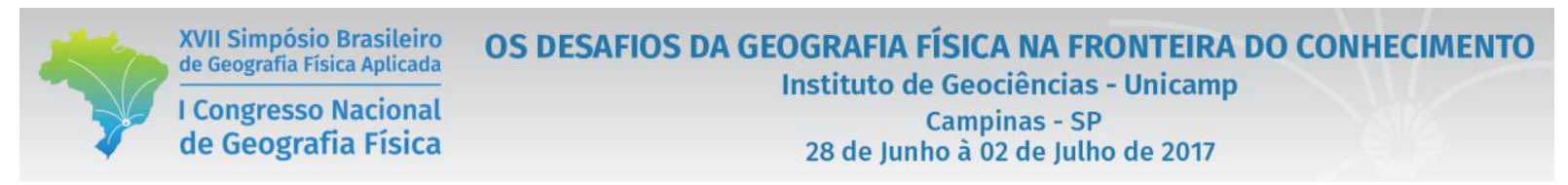

A lógica de consumo está entrelaçada a dinâmicas culturais em que a aquisição de determinados produtos se dá no sentido de dotar o consumidor de sinais de diferenciação. São estabelecidas redes sociais de grupos de pertencimento que se distinguem pela capacidade de consumo. O consumo de produtos específicos funciona como comunicação social e fator cultural importante para a afirmação da identidade. Os investimentos que há décadas foram maciçamente destinados ao processo de produção passam a ser canalizados à publicidade para garantir o público alvo, sendo realizados altos investimentos em propaganda e marketing para estimular o consumo. Muitos comerciais chegam a omitir o uso do produto e o design e a marca são enaltecidos para destacar o produto. Nesse contexto, Santos $(2001$, p. 48) avalia que:

Atualmente as empresas hegemônicas produzem o consumidor antes mesmo de produzir os produtos. Um dado essencial do entendimento do consumo é que a produção do consumidor, hoje, precede à produção dos bens e dos serviços. [...] daí o império da informação e da publicidade. Tal remédio teria $1 \%$ de medicina e $99 \%$ de publicidade [...]. (SANTOS, 2001, p. 48).

Até mesmo os signos são manipulados de tal sorte que as aquisições das mercadorias são vinculadas a possibilidades de vivenciar conquistas amorosas, saúde, poder, beleza, aventura e sucesso. A ideia transmitida é a de que a obtenção de determinadas mercadorias possibilita a transferência destas características para o consumidor. Alguns autores fazem referência aos supostos sentimentos de prazer e felicidade ao se adquirir mercadorias e a insaciabilidade na busca por objetos novos. Sevcenko (2001, p. 88), ao problematizar este aspecto, afirma que “[...] na sociedade da mercadoria, o consumismo seria proposto como a terapia por excelência para avaliar o mal-estar gerado pela própria essência desse sistema, centrado no mercado e não nos valores humanos".

Segundo relatos históricos populares, os objetos eram produzidos para serem duráveis e úteis. As famílias conservavam objetos que passavam de geração para geração, os quais tinham um valor afetivo e eram guardados em respeito à memória dos antepassados. Hoje, essa realidade mudou e os objetos se tornaram descartáveis.

De acordo com o conceito de Costa (2004, p. 174),

[...] os objetos, é verdade, se tornaram cada vez mais descartáveis. Mas não apenas porque o mercado os destina à obsolescência precoce, e sim porque já não temos mais quem herde o sentido moral e emocional que eles, um dia, materializaram. Os objetos, hoje como ontem, servem para ostentar a opulência de seus possuidores. O contrário de ontem, porém, não mais se prestam a função de manter viva a história de quem os possuiu. $O$ 'a quem interessar possa' perdeu a razão de ser. Enquanto vivemos, os usamos como excitantes das sensações; depois que morremos, ou eles têm valor de mercado e são vendidos ou não têm liquidez e vão para o lixo. (COSTA, 2004, p. 174, grifo do autor). 
Portanto, no presente momento da globalização, faz-se necessário refletir sobre uma revisão dos padrões de consumo da sociedade contemporânea que prime pela valorização da natureza a partir de uma conscientização humanitária capaz de substituir o atual estilo de vida insustentável, valorizando a qualidade e o equilíbrio dos recursos naturais.

\section{Resíduos sólidos e os problemas sanitários}

A questão dos resíduos sólidos urbanos é absolutamente urgente, dada a dimensão catastrófica da situação nos municípios e nas regiões metropolitanas, onde a gestão dos resíduos e seus locais de disposição são, em muitos casos, impróprios, o que coloca em risco o meio ambiente e a saúde das populações afetadas, uma vez que o lixo é, também, o ambiente perfeito para a proliferação de doenças.

A definição de resíduos sólidos é algo complexo, visto que existem diversos conceitos, o que dificulta a seleção dos resíduos para a sua disposição final. Segundo a Associação Brasileira de Normas Técnicas (2004, p. 1), resíduos sólidos são definidos como "resíduos nos estados sólidos e semi-sólidos, que resultam de atividades de origem industrial, doméstica, hospitalar, comercial, agrícola, de serviços e de varrição."

Normalmente, as publicações sobre resíduos sólidos se utilizam indistintamente dos termos "lixo" e "resíduos sólidos". Resíduo sólido ou simplesmente "lixo" é todo material sólido ou semi-sólido indesejável e que necessita ser removido, por ter sido considerado inútil por quem o descarta, para qualquer recipiente destinado a este ato.

O destino do lixo deve ser diferente de acordo com cada tipo de resíduo que o constitui. Assim, o destino mais comum que se dá para qualquer resíduo no Brasil são os chamados "lixões". A Pesquisa Nacional de Saneamento Básico, realizada pelo Instituto Brasileiro de Geografia e Estatística (IBGE, 2000), aponta que, de todo o lixo coletado nos municípios brasileiros, $47 \%$ tem como disposição final os aterros sanitários, $22,3 \%$, os aterros controlados, e 30,5\%, os lixões.

Os lixões são espaços abertos, geralmente, localizados na periferia das cidades, onde o lixo fica apodrecendo ou é queimado. O lixão é uma forma inadequada de disposição final de resíduos sólidos, que se caracteriza pela simples descarga do lixo sobre o solo, sem medidas de proteção ao meio ambiente ou à saúde pública. Caracteriza-se como descarga de resíduos a céu aberto.

A cidade de Palmelo (GO) possui um modelo de lixão conforme o citado acima. Os moradores desprezam o lixo em tambores, sem nenhuma cautela de separação, cabendo ao poder público a responsabilidade de recolhê-lo. Este é, então, desprezado em um lixão que fica a pouco mais de 500 metros de distância do 
leito do Ribeirão Caiapó, uma vez que esse curso d'água é o responsável pelo abastecimento público do município de Palmelo (GO).

Por não se adotar um método que contemple critérios sanitários ou ecológicos, provoca-se a contaminação das águas subterrâneas, do solo e a poluição do ar com gases tóxicos.

O lixo séptico ou hospitalar deve ir para valas sépticas ou ser incinerado (a incineração é diferente da queima, pois é feita em máquinas especiais e não simplesmente pelo fogo). Em Palmelo (GO), o lixo hospitalar é depositado no lixo.

Convém reafirmar que o lixo é, também, o ambiente ideal para a proliferação de doenças. Quando disposto no solo sem nenhum tratamento, o lixo atrai para si dois grandes grupos de seres vivos: os macrovetores e os microvetores. Fazem parte do grupo dos macrovetores, por exemplo, moscas, baratas, ratos, porcos, cachorros e urubus. Os microvetores, como as bactérias, fungos e vírus, por sua vez, são considerados de grande importância epidemiológica por serem patogênicos e, consequentemente, nocivos ao homem.

A transmissão de doenças por meio do lixo pode ocorrer por via direta e, sobretudo, por via indireta.

A transmissão direta: ocorre por meio de micro-organismos tais como bactérias, vírus, protozoários e vermes. Esses micro-organismos patogênicos quando presentes no lixo sobrevivem por algum tempo, podendo transmitir doenças àqueles que manuseiam o lixo. A transmissão indireta: essa forma de transmissão pode alcançar uma quantidade maior de pessoas, pois se dá pela contaminação do ar, da água e do solo por vetores de doenças como insetos. (BRASIL, 2009, p. 28).

A saúde da população pode ser afetada por ejeções líquidas e gasosas do lixo que infectam o ar; pela emissão de material particulado e de gases tóxicos e mal cheirosos, decorrentes da queima do lixo ou do seu processo de decomposição biológica; pela contaminação da água e pelo chorume - líquido de coloração escura gerado pela decomposição do lixo, que contém matéria orgânica, metais pesados, enzimas e micro-organismos.

A Constituição Federal de 1988, em seu artigo 255, legisla que "todos têm direito ao meio ambiente ecologicamente equilibrado, bem de uso comum e essencial à sadia qualidade de vida, impondo-se ao poder público e a coletividade o dever de defendê-lo e preservá-lo para as presentes e futuras gerações." (BRASIL, 2010, p. 15).

Dessa forma, a Constituição Federal realiza a divisão de responsabilidades, impondo a cada agente social obrigações para a eficácia da gestão de resíduos sólidos. Porém, sabe-se que a legislação nem sempre é cumprida; é o caso específico da legislação ambiental. As empresas, em geral, e o próprio Governo são, 
muitas vezes, os primeiros a violarem as leis ambientais, invadindo o espaço público para defender os interesses privados e econômicos.

Vê-se que o ambiente é um bem coletivo e, para fazer valer os nossos direitos, é preciso conhecer um pouco de Geoecologia e política ambiental, a qual é vista não apenas como política de Governo, mas como parte das políticas voltadas para o interesse da maioria das sociedades.

\section{Considerações}

Ao fazer observação da área específica do município de Palmelo (GO), uma região inserida nas paisagens da Região do Cerrado, mais especificamente em uma área utilizada para servir de "Lixão", percebe-se que não se faz uso do solo ambientalmente correto, pois o terreno não foi devidamente projetado para receber os resíduos, abriu-se enormes valas e o lançamento dos resíduos são feitos in natura a céu aberto.

Ficou constatado que cerca de 2 toneladas resíduos chegam diariamente ao lixão. Os resíduos apresentam matéria orgânica, materiais recicláveis como plásticos, metais, papeis, garrafas pet, metais ferrosos, vidros e resíduos provenientes de construção civil. Foi visto significante quantidade de materiais recicláveis ali dispostos, principalmente plásticos.

Queimadas e presença de animais domésticos são constantes, pois convivem juntos com as pessoas catadoras no lixão. Diante da evidências inferiu-se que não existe a coleta seletiva e que muitos dos materiais descartados no lixão poderiam ser reutilizados, fato que possivelmente corrobora com o Plano Estadual de Gestão Integrada de Resíduos Sólidos (PEGIRS).

Contudo como forma de evitar que todo resíduo produzido e coletado permaneça no lixão, o poder público municipal de Palmelo (GO), incentiva os catadores pagando a eles um salário mensal somado ao valor obtido com a venda dos dejetos separados no lixão que é totalmente revertido para os catadores, exceto a isto nada mais foi proposto a fim de envolver a sociedade no princípio da responsabilidade compartilhada.

Dessa forma se faz necessário implantar a coleta seletiva, a fim de diminuir a quantidade dos resíduos depositados em locais inadequados. Ressalta-se que a participação efetiva do poder público em parceria com a sociedade civil é de suma importância para buscar mecanismos e instrumentos que possam equacionar os problemas socioambientais que afetam de forma direta ou indiretamente o ambiente e a saúde, e assim proporcionar a todos um ambiente equilibrado e uma melhor qualidade de vida.

\section{Bibliografia}




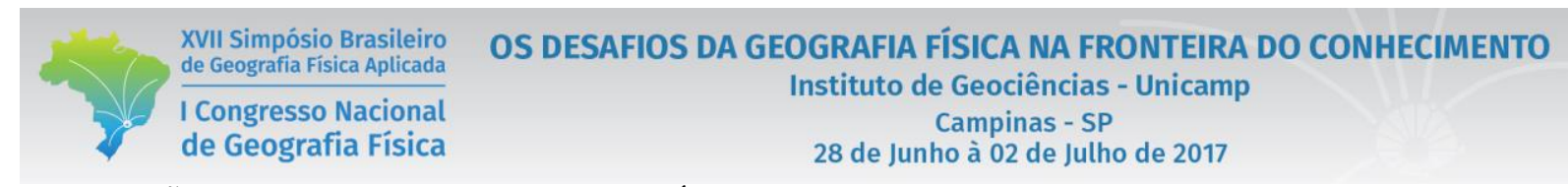

ASSOCIAÇÃO BRASILEIRA DE NORMAS TÉCNICAS. NBR 10004: Resíduos sólidos - Classificação. Rio de Janeiro: ABNT, 2004.

BAUMAN, Zygmunt. Vida líquida. Rio de Janeiro: Zahar, 2007.

BERNARDES, Júlia Adão; FERREIRA, Francisco Pereira. Sociedade e natureza. In: CUNHA, Sandra Baptista da; GUERRA, Antonio Jose Teixeira (Org.). A questão ambiental: diferentes abordagens. Rio de Janeiro: Bertrand Brasil, 2003. p. 17-42.

BRASIL. Constituição (1988). Constituição da República Federativa do Brasil. 15. ed. rev. ampl. e atual. São Paulo: Revista dos Tribunais, 2010. (Atualizada até a Emenda Constitucional n. 62/2009).

BRASIL. Fundação Nacional de Saúde. Resíduos sólidos e a saúde da comunidade: informações técnicas sobre a inter-relação saúde, meio ambiente e resíduos sólidos. Brasília: Funasa, 2009.

COSTA, Jurandir Freire. O vestígio e a aura: corpo e consumismo na moral do espetáculo. Rio de Janeiro: Garamond, 2004.

GOLDEMBERG, José. Resíduos sólidos: o caminho para a sustentabilidade. In: SANTOS, Maria Cecilia Loschiavo dos; LOPES, Sylmara; GONÇALVES-DIAS, Francelino (Org.). Resíduos sólidos urbanos e seus impactos socioambientais. São Paulo: IEE-USP, 2012. p. 14-17.

IBGE - Instituto Brasileiro de Geografia E Estatística. Diretoria de Pesquisas, Departamento de População e Indicadores Sociais. Pesquisa Nacional de Saneamento Básico 2000. Rio de Janeiro: IBGE, 2000. Disponível em: <http://www.ibge.gov.br/home/presidencia/notícias/27032002pnsb.shtm>. Acesso em: 20 jul. 2016.

JACOBI, Pedro Roberto. Desafios e reflexões sobre resíduos sólidos nas cidades brasileiras. In: SANTOS, Maria Cecilia Loschiavo dos; LOPES, Sylmara; GONÇALVES-DIAS, Francelino (Org.). Resíduos sólidos urbanos e seus impactos socioambientais. São Paulo: IEE-USP, 2012. p. 31-34.

MALTHUS, Thomas Roberto. Na essay on the principal of population. 1798. Tradução de CURY, Antonio Alves. Ensaio sobre a população. Traduzido de Population: The First Essay. Ann Arbor Paperbacks, The university of Michigan Press, 1959. p. 8. < file:///C:/Users/usuario/Downloads/Ensaio+sobre+a+popula\%C3\%A7\%C3\%A3o++Malthus\%20(2).pdf>. Acesso em 12 de jan. 2017.

OLIVA JUNIOR, Elenaldo Fonseca de; FREIRE, Raiane Souza. Os impactos ambientais decorrentes da produção de resíduos sólidos urbanos e seus riscos à saúde. Revista Eletrônica José Augusto Vieira, ano VI, n. 8, p. 158-171, set. 2013. Disponível em: 〈http://fjav.com.br/revista/Downloads/edicao08/Artigo_158_171.pdf〉. Acesso em: 12 jul. 2016.

SANTOS, Milton. Por uma outra globalização: do pensamento único à consciência universal. 6. ed. Rio de Janeiro: Record, 2001.

SANTOS, Milton. A natureza do espaço: técnica e tempo, razão e emoção. 4. ed., 2. reimpr. São Paulo: Editora da Universidade de São Paulo, 2006.

SEVCENKO, Nicolau. A corrida para o século XXI: no loop da montanha-russa. São Paulo: Companhia das Letras, 2001.

SOUZA, Líria Alves de. Impactos ambientais. Brasil Escola. 2016. Disponível em: <http://brasilescola.uol.com.br/quimica/impactos-ambientais.htm>. Acesso em: 14 jul. 2016. 